Acta vet. scand. $1986,27,124-137$.

From the Department of Internal Medicine I, Division of Parasitology, Norwegian College of Veterinary Medicine, Oslo, Norway.

\title{
EFFICACY OF TOLTRAZURIL IN THE PREVENTION OF COCCIDIOSIS IN NATURALLY INFECTED LAMBS ON PASTURE
}

\author{
By \\ Bjørn Gjerde and Oddvar Helle
}

\begin{abstract}
GJERDE, B. and O. HELLE: Efficacy of toltrazuril in the prevention of coccidiosis in naturally infected lambs on pasture. Acta vet. scand. 1986, 27, 124-137. — The efficacy of toltrazuril (Bay Vi 9142) in preventing ovine coccidiosis due to an infection acquired immediately after turnout on pasture was evaluated by comparing the faecal consistency, weight gain, and oocyst output of treated and untreated lambs in 3 trials. The lambs were either given a single treatment with toltrazuril at 15 or $20 \mathrm{mg} / \mathrm{kg}$, or they were given a dose of $10 \mathrm{mg} / \mathrm{kg}$ on 2 separate days. A single treatment with toltrazuril at $20 \mathrm{mg} / \mathrm{kg}$ on day 10 after turnout on pasture almost completely prevented coccidiosis in 2 trials. In a third trial the acute phase of a severe Nematodirus battus infection coincided with the outbreak of coccidiosis, and thus partly masked the clinical effect of the anticoccidial treatment. In lambs treated with toltrazuril at $15 \mathrm{mg} / \mathrm{kg}$ on day 10 after turnout, the coccidial infection caused a softening of the faeces, but the lambs were not severely affected by the coccidia. In lambs given a dose of $10 \mathrm{mg} / \mathrm{kg}$ of toltrazuril twice, either on days 10 and 11 after turnout, or on days 10 and 20 , the coccidial infection caused a softening af the faeces, including some cases of diarrhoea. Oocyst production due to the initial coccidial infection on pasture was markedly reduced by all treatments with toltrazuril. The reduction was most pronounced after a dose of $20 \mathrm{mg} / \mathrm{kg}$. Lambs treated with single doses of 15 or $20 \mathrm{mg} / \mathrm{kg}$ of toltrazuril had a better weight gain than the untreated controls in 2 of the trials. Lambs treated with toltrazuril on day 10 after turnout were partially resistant to the coccidial reinfection acquired immediately after treatment, and they had a similar level of immunity as the untreated controls to the subsequent reinfection on pasture.
\end{abstract}

Eimeria spp.; sheep; prophylactic medication; B a V Vi 9142 ; immunity; Nematodirus battus.

In Norway, ovine coccidiosis due to infection with Eimeria spp. typically occurs in young lambs $2-3$ weeks after they have been turned out on pastures grazed by sheep at a high stocking rate in previous years. The lambs become infected through ingestion of overwintered coccidial oocysts during their first 
days on pasture (Helle 1970, Helle \& Hilali 1973), which explains the short interval of 12-16 days between turnout and the onset of clinical signs, and the fairly synchronous occurrence of the disease in a given flock. The lambs are highly susceptible to the initial coccidial infection on pasture, since they have had very little previous exposure to coccidia, and probably also because of the stress associated with being turned out on pasture. Clinical features of coccidiosis include diarrhoea of 1 to 1 days' duration, dehydration, impaired weight gain, or weight loss, and death in some cases (Helle 1964, Helle 1970, Helle 1971),

On pastures where coccidiosis occurs, the majority of the lambs are usually affected, and hence coccidiosis may cause considerable economic losses. Coccidiosis in lambs can largely be controlled by turning the lambs out on pastures not grazed by sheep in the previous grazing season. However, on most farms in this country such pastures are not available in the spring, making prophylactic medication an important measure in the control of coccidiosis.

Because coccidiosis occurs in young suckling lambs, anticoccidial drugs supposed to be given continuously in feed or drinking water are not suitable for prophylactic medication. Instead, the drug must be given individually to the lambs. Hence, it would be preferable to use an anticoccidial compound capable of controlling the severity of, or preventing, coccidiosis after a single application. So far, such a drug has not been available. The anticoccidial drug currently used in Norway, sulphadimidine, is usually administered on 2 or 3 consecutive days, beginning on day 12 after turnout on pasture, but this drug is not always fully effective in preventing coccidiosis (Helle 1981). Recently, two new and closely related compounds, the symmetrical triazinone derivatives Bay Vg 7183 and Bay Vi 9142, have been reported to have a high activity against several avian and mammalian Eimeria spp., even after a single or a few applications of either drug (Haberkorn \& Schulz 1981, Mehlhorn et al. 1984). Thus, Bay Vg 7183 was reported to bring about a marked reduction in the oocyst shedding of 2 experimentally infected lambs when given daily at $5 \mathrm{mg} / \mathrm{kg}$ from day 6 to day 10 after an infection with several Eimeria spp. (Haberkorn \& Schulz 1981). The present paper describes an investigation of the effectiveness of Bay Vi 9142 (tolrazuril) in preventing coccidiosis in naturally infected lambs on pasture. 


\section{MATERIALS AND METHODS \\ Experimental animals}

A total of 175 lambs (mostly twins) of the Dala breed, kept together with their mothers, were used in the trials. Ewes and lambs were housed in pens with slatted floors from lambing time until they were turned out on pasture on day 0 of the trials. The lambs were from 1 to 5 weeks old at turnout and were randomly assigned to experimental groups.

\section{Coccidial infections}

The lambs were supposed to acquire a natural coccidial infection through ingestion of overwintered Eimeria spp. oocysts immediately after they had been turned out on contaminated pastures, i.e. pastures grazed by sheep in the previous grazing seasons. Trial 1 (in 1984) and Trial 2 (in 1985) were carried out on a pasture at Dal Research Farm, Heggedal, whereas Trial 3 (in 1985) was carried out on a pasture at the Agricultural University of Norway, Ås.

In addition to the continuous natural reinfection of all the lambs on pasture, 11 lambs were each experimentally inoculated with about 1 million sporulated Eimeria spp. oocysts in the second part of Trial 1. Oocysts for the experimental infection were isolated from the faeces of untreated control lambs in the first part of Trial 1. After sporulation in a potassium bichromate solution, the oocysts were concentrated by sugar flotation, washed by repeated centrifuging, and given to the lambs with a stomach tube.

\section{Anticoccidal medication}

An aquous suspension of toltrazuril (Bay Vi 9142) was given orally to the lambs by means of a stomach tube. In Trial 1, a $1 \%(\mathrm{w} / \mathrm{v})$ suspension, and in Trials 2 and 3 , a $0.75 \%$ suspension of the drug was used. The lambs were accurately dosed according to their body weight.

\section{Experimental design}

Trial 1. The first part of the trial (from turnout till day 34 after turnout) comprised 46 lambs assigned to 4 groups, which were treated as shown in Table 1. Faecal samples were collected on days $10,13,15,17,20,23,28$, and 34 after turnout. 
To determine their weight gains in different periods, the lambs were weighed on 9 occasions during the trial.

The second part of the trial (from day 34 till day 90 after turnout) comprised the 22 lambs in groups 1 and 2 (Table 1). The purpose of this part of the trial was to evaluate whether the treatment wiht toltrazuril on day 10 after turnout had impeded the lambs' acquisition of immunity to coccidia and rendered them more susceptible to reinfections with coccidia. Thus, on day 49 after turnout, 5 lambs in group 1 (nonmedicated) and 6 lambs in group 2 (toltrazuril-treated) were each orally inoculated with about 1 million sporulated Eimeria spp. oocysts. Faecal samples were collected on days $49,62,69,76$, and 90 after turnout, and the lambs were weighed on 5 occasions.

T ri al 2. The trial comprised 57 lambs assigned to 3 groups, which were treated as sohwn in Table 4. Faecal samples were collected on days $14,17,21,28$, and 35 after turnout, and the lambs were weighed on 7 occasions during the trial. On day 17 after turnout a presumptive diagnosis of a rather severe Nematodirus battus infection was made, and 10 randomly chosen lambs in each of the 3 groups were therefore given an anthelmintic treatment with morantel citrate the same day. Only 30 of the 57 lambs in the trial were dosed with an anthelmintic in an attempt to determine the severity of the $\mathrm{N}$. battus infection from the subsequent faecal egg counts of the undosed lambs, and the relative importance of $\mathrm{N}$. battus as a cause of abnormal faeces in the different groups.

T ri a l 3. The trial comprised 72 lambs assigned to 3 groups, which were treated as in Trial 2 (Table 7). Faecal samples were collected only on day 20 after turnout, and the lambs were weighed only on 4 occasions.

\section{Faecal examinations}

Faecal samples were taken from the rectum of each lamb. On most sampling days it was not possible to obtain adequate faecal samples from all lambs. Hence, on some sampling days, the number of faecal samples from a given group is somewhat smaller than the actual number of lambs in that group.

Each faecal sample was given a faecal consistency score according to the following criteria: $1=$ normal pelleted faeces; $2=$ soft pelleted faeces; $3=$ pastelike faeces; $4=$ diarrhoea. The number of oocysts and the number of nematode eggs per 
gram of faeces (faecal oocyst count and egg count, respectively) were determined by a modified McMaster technique as described by Helle (1964).

\section{Statistical examinations}

Analysis of variance was used to test for significant differences between the groups in each trial with respect to daily weight gain during different periods, faecal consistency score, and number of oocysts per gram of faeces (OPG). The 2 last-mentioned variables were compared either on the basis of observations from a single sampling day, or from pooled observations from 2 or more consecutive sampling days. Analysis of variance on oocyst count was performed on the log-transformed oocyst count, i.e. on the variable $\log (O P G+50)$. Analysis of variance was performed by the General Linear Models (GLM) procedure with Duncan's multiple range test in the Statistical Analysis System (SAS User's Guide: Statistics 1982 Edition, SAS Institute Inc., U.S.A.). The level of significance was 0.05 .

\section{Trial 1}

\section{RESULTS}

All treatments with toltrazuril caused a marked reduction in the number of oocysts excreted (Table 1). On day 13 after turnout, only group 2 differed significantly from the controls, but from day 15 onwards all treated groups had significantly lower faecal oocyst counts than group 1. Group 2 showed the greatest reduction in oocyst counts, followed by group 3 and group 4.

None of the lambs in group 2 had diarrhoea during the first part of the trial, whereas 4 lambs in group 1, 3 lambs in group 3, and 5 lambs in group 4 had diarrhoea on 1 or more sampling days after the time of treatment. When the observations from the 6 sampling days from day 15 onwards were pooled, the frequencies of faecal samples with a soft consistency (pastelike or diarrhoeic) in the the different groups were as follows: (1) $53.5 \%$, (2) $23.2 \%$, (3) $44.3 \%$, and (4) $33.3 \%$. Similarly, group 2 had the lowest mean faecal consistency score on most sampling days (Table 2). The faecal consistency score of this group was significantly lower than that of the controls on days 20 and 34 , and when the data from all sampling days from day 


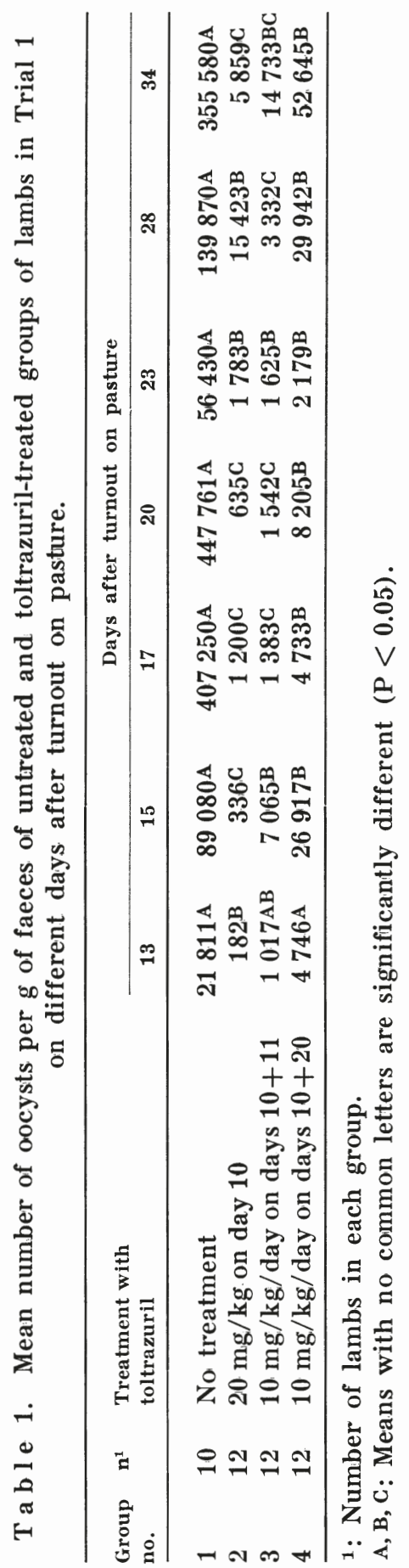


T a b l e 2. Mean faecal consistency scores of untreated and toltrazuriltreated groups of lambs on 6 sampling days considered separately and collectively. The faecal consistency was classified as follows: $1=$ normal pelleted faeces; $2=$ soft pelleted faeces; $3=$ pastelike faeces; $4=$ diarrhoea.

\begin{tabular}{lccccccc}
\hline \multirow{2}{*}{$\begin{array}{l}\text { Group } \\
\text { no. }\end{array}$} & \multicolumn{8}{c}{ Days after } & turnout & on pasture \\
\cline { 2 - 8 } & 15 & 17 & 20 & 23 & 28 & 34 & $15-34$ \\
\hline 1 & 2.00 & 2.38 & $2.80 \mathrm{~A}$ & 2.60 & 2.00 & $2.60 \mathrm{~A}$ & $2.40 \mathrm{~A}$ \\
2 & 1.42 & 1.33 & $1.91^{\mathrm{B}}$ & 1.75 & 1.64 & $1.55^{\mathrm{B}}$ & $1.59 \mathrm{C}$ \\
3 & 1.50 & 2.33 & $2.58 \mathrm{AB}$ & 1.92 & 1.92 & $2.00 \mathrm{AB}$ & $2.06 \mathrm{AB}$ \\
4 & 1.44 & 2.08 & $2.91 \mathrm{~A}$ & 2.00 & 1.75 & $1.50^{\mathrm{B}}$ & $1.97^{\mathrm{B}}$ \\
\hline
\end{tabular}

1: Treated as shown in Table 1.

A, B, C: Means with no common letters are significantly different $(\mathrm{P}<0.05)$.

15 onwards were pooled. The faecal consistency scores of group 3 did not differ significantly from those of the control group. In group 4, the first dose of toltrazuril on day 10 did not seem to prevent a softening of the faeces, but the second dose of the drug on day 20 seemed to improve the faecal consistency of these lambs (Table 2).

There were no significant differences between the groups during any periods of the trial with respect to daily weight gain (Table 3).

In the second part of Trial 1 , there were no significant differences between the 4 secondary groups derived from groups 1 and 2 with respect to oocyst counts, faecal consistency score, and weight gain. All the secondary groups had moderate oocyst

T a b l e 3. Mean daily weight gains (in grams) of untreated and tiltrazuril-treated groups of lambs in Trial 1 in different periods after turnout on pasture.

\begin{tabular}{lccccc}
\hline \multirow{2}{*}{$\begin{array}{l}\text { Group } \\
\text { no. }\end{array}$} & \multicolumn{5}{c}{ Periods; days after turnout } \\
\cline { 2 - 6 } & $6-13$ & $13-20$ & $20-28$ & $28-34$ & $10-34$ \\
\hline & 330 & 197 & 294 & 237 & 263 \\
2 & 357 & 261 & 289 & 200 & 267 \\
3 & 315 & 239 & 299 & 242 & 274 \\
4 & 336 & 173 & 325 & 222 & 263 \\
\hline
\end{tabular}

1: Treated as shown in Table 1. Because of mastitis in 2 ewes, the data on weight gain of 2 lambs in each of groups 2 and 4 were omitted. 
counts on all sampling days. Two challenged untreated lambs and 3 challenged toltrazuril-treated lambs had diarrhoea on day 13 after inoculation, whereas none of the unchallenged lambs had diarrhoea, suggesting that the occurrence of abnormal faeces was due to the experimental reinfection. Similarly, both challenged secondary groups had somewhat higher mean faecal consistency scores than the unchallenged ones on day 13 after inoculation, but all secondary groups had a moderate consistency score on day 20 after inoculation.

\section{Trial 2}

Both toltrazuril-treated groups had significantly lower faecal oocyst counts than the untreated controls on all sampling days (Table 4). Moreover, on some sampling days group 3 had a significantly lower oocyst count than group 2.

T a b l e 4. Mean number of oocysts per $g$ of faeces of untreated and toltrazuriltreated groups of lambs in Trial 2 on different days after turnout on pasture.

\begin{tabular}{|c|c|c|c|c|c|c|c|}
\hline \multirow{2}{*}{$\begin{array}{l}\text { Group } \\
\text { no. }\end{array}$} & \multirow{2}{*}{$\mathbf{n}^{1}$} & \multirow{2}{*}{$\begin{array}{l}\text { Treatment with } \\
\text { toltrazuril }\end{array}$} & \multicolumn{5}{|c|}{ Days after turnout on pasture } \\
\hline & & & 14 & 17 & 21 & 28 & 35 \\
\hline 1 & 19 & No treatment & $386750^{A}$ & $1051506^{A}$ & $651068 \mathrm{~A}$ & $377111^{A}$ & $307076 \mathrm{~A}$ \\
\hline 2 & 19 & $15 \mathrm{mg} / \mathrm{kg}$ on day 10 & 20279 B & 8722 B & $10506^{B}$ & $17965^{\mathrm{B}}$ & $68984^{B}$ \\
\hline 3 & 19 & $20 \mathrm{mg} / \mathrm{kg}$ on day 10 & $10850^{\mathrm{B}}$ & $464 \mathrm{C}$ & $7871^{B}$ & $4121^{C}$ & $14608 \mathrm{C}$ \\
\hline
\end{tabular}

${ }^{1}$ : Number of lambs in each group.

A, B, C: Means with no common letters are significantly different $(P<0.05)$.

On day 14 after turnout, 2 of 55 examined lambs had eggs of Nematodirus battus in their faeces, whereas on day 17, eggs of $\mathrm{N}$. battus $(50-600 \mathrm{eggs} / \mathrm{g})$ occurred in he faecal samples from 28 out of 52 examined lambs. Among the lambs dosed with an anthelmintic on day 17, all but 2 had negative faecal egg counts on the following sampling days. The undosed lambs, on the other hand, had an average faecal $N$. battus egg count of 285 eggs/g (range: 0-1000 eggs) on day 21, and an average egg count of $680 \mathrm{eggs} / \mathrm{g}$ (range: $0-1700 \mathrm{eggs}$ ) on day 28.

There were no significant differences between the groups on any single sampling day with respect to faecal consistency score, but both toltrazuril-treated groups had lower scores than the controls on days 21 and 28 (Table 5). Moreover, when the observations from all sampling days were pooled, both treated 
Table 5. Mean faecal consistency scores $^{1}$ of untreated and toltrazuril-treated groups of lambs in Trial 2 on 5 different sampling days considered separately and collectively. The lambs in this trial were rather severely infected with Nematodirus battus.

\begin{tabular}{lcccccc}
\hline $\begin{array}{c}\text { Group } \\
\text { no. }\end{array}$ & \multicolumn{7}{c}{ Days after turnout on pasture } \\
\hline 1 & 14 & 17 & 21 & 28 & 35 & $14-35$ \\
2 & 1.72 & 3.00 & 3.05 & 2.00 & 1.71 & $2.29 \mathrm{~A}$ \\
3 & 1.41 & 2.61 & 2.72 & 1.18 & 1.75 & $1.95^{\mathrm{B}}$ \\
\hline
\end{tabular}

${ }^{1}$ : Classification of faecal consistency as in Table 2.

2: Treated as shown in Table 4.

A, B: Means with no common letters are significantly different $(\mathrm{P}<0.05)$.

groups had significantly lower faecal consistency scores than the controls (Table 5). Five lambs in each group had diarrhoea on day 17 after turnout, whereas 7 lambs in group 1, 2 lambs in group 2, and 3 lambs in group 3 had diarrhoea on day 21. When all sampling days were considered collectively, the frequencies of faecal samples with a soft consistency in the different groups were as follows: (1) $47.2 \%$, (2) $34.9 \%$, and (3) $29.8 \%$.

Both toltrazuril-treated groups had better daily weight gains than the controls after the time of treatment (Table 6). The differences were significant in the period from day 14 till day 28 after turnout.

T a b l e 6. Mean daily weight gains (in grams) of untreated and toltrazuril-treated groups of lambs in Trial 2 in different periods after turnout on pasture.

\begin{tabular}{lcccccc}
\hline \multirow{2}{*}{$\begin{array}{l}\text { Group } \\
\text { no.1 }\end{array}$} & \multicolumn{6}{c}{ Periods; days after turnout on pasture } \\
\cline { 2 - 7 } & $7-14$ & $14-21$ & $21-28$ & $28-35$ & $14-28$ & $10-35$ \\
\hline 1 & 341 & 46 & 259 & 257 & 152 B & 206 \\
2 & 323 & 138 & 335 & 293 & 236 A & 262 \\
3 & 320 & 168 & 305 & 275 & 236 A & 258 \\
\hline
\end{tabular}

1: Treated as shown in Table 4.

$A, B$ : Means with no common letters are significantly different $(\mathrm{P}<0.05)$.

The anthelmintic treatment on day 17 had no significant effect on the faecal consistency or weight gain of the lambs in the 3 weeks following medication. 


\section{Trial 3}

Both toltrazuril-treated groups had significantly lower oocyst counts and significantly lower faecal consistency scores than the controls on day 20 after turnout (Table 7). Nine untreated lambs had diarrhoea, whereas only 1 lamb in each of groups 2 and 3 had diarrhoea on day 20. However, 9 lambs in group 2 had pastelike faeces compared with 2 lambs in group 3 . Both treated groups had significantly better weight gains than the controls from day 10 to day 20 after turnout (Table 7 ).

T a b l e 7. Mean number of oocysts per $g$ of faeces (OPG) and mean faecal consistency scores $(\mathrm{FCS})^{1}$ on day 20 after turnout, and mean daily weight gains (WG) in $\mathrm{g}$ from day 10 till day 20 after turnout for untreated and toltrazuril-treated groups of lambs in Trial 3.

\begin{tabular}{lllrll}
\hline $\begin{array}{l}\text { Group } \\
\text { no. }\end{array}$ & $\mathrm{n}^{2}$ & $\begin{array}{l}\text { Treatment with } \\
\text { toltrazuril }\end{array}$ & OPG & FCS & WG \\
\hline 1 & 24 & No treatment & $935887^{\mathrm{A}}$ & $3.42 \mathrm{~A}$ & $183 \mathrm{~B}$ \\
2 & 24 & $15 \mathrm{mg} / \mathrm{kg}$ on day 10 & $56382^{\mathrm{B}}$ & $2.05^{\mathrm{B}}$ & $250^{\mathrm{A}}$ \\
3 & 24 & $20 \mathrm{mg} / \mathrm{kg}$ on day 10 & $6364^{\mathrm{B}}$ & $1.36^{\mathrm{C}}$ & $279^{\mathrm{A}}$ \\
\hline
\end{tabular}

1: Classification of faecal consistency as in Table 2.

2 Number of lambs in each group.

A, B, C: Means with no common letters are significantly different $(\mathrm{P}<0.05)$.

\section{DISCUSSION}

The investigation showed that treatment of lambs with toltrazuril on day 10 after turnout on pasture prevented the massive production of oocysts that the initial coccidial infection on pasture normally gives rise to. The reduction in oocyst production was dose related, toltrazuril at a dose level of $20 \mathrm{mg} / \mathrm{kg}$ being more effective than dose levels of either 10 or $15 \mathrm{mg} / \mathrm{kg}$ when compared in the same trial. The low oocyst output of the treated lambs during the first 2 weeks after medication demonstrated a high activity of toltrazuril against the various developmental stages of the Eimeria spp. infecting the lambs. Previous investigations have also clearly shown that toltrazuril (Bay $\mathrm{Vi}$ 9142) and the preceding, closely related compound Bay Vg 7183 have a very high activity against all intracellular stages (schizogonic stages and gamonts) of different Eimeria spp. (Haberkorn \& Stoltefuss 1984, Haberkorn \& Schulz 1981, Mehlhorn et al. 1984). 
The oocyst counts of the treated lambs in Trials 1 and 2 were still at a low to moderate level about 3 weeks after treatment. Moreover, the toltrazuril-treated lambs that were monitored for a further 8 weeks on pasture in Trial 1, including those given an experimental challenge infection, had moderate oocysts counts throughout this period. Host immunity to Eimeria spp. is mainly induced by the developing asexual stages (schizonts) of the parasites (Rose 1982). The coccidia would therefore have had time to induce a certain level of immunity in the lambs before a large proportion of them were eliminated by the treatment on day 10 after turnout. One of the effects of host immunity to coccidia is to reduce the number of oocysts produced from a given infection (Rose 1982). In the toltrazuril-treated lambs no massive oocyst production or clinical signs arose from the coccidial infection they presumably acquired shortly after treatment, or from the continuous reinfection later in the grazing season. This suggests that the anticoccidial treatment had not impeded their acquisition of immunity to these parasites.

On pastures contaminated by coccidia, lambs may show signs of coccidiosis as early as about 12 days after turnout. Hence, to be fully effective in preventing clinical signs, treatment should be given no later than on day $\mathbf{1 0}$ after turnout. Treatment on day 10 after turnout may even be a little late in the course of the infection, especially if the lambs should acquire a heavy infection immediately after they have been led out on pasture. Moreover, smaller doses of toltrazuril than those used in the present trials may suffice if the lambs were treated earlier than on day 10 after turnout, since fewer developing coccidia would be present in the intestinal mucosa of the lambs at an earlier time of treatment. However, treatment much earlier than on day 10 after turnout may render the lambs more susceptible (less immune) to the subsequent reinfection on pasture. Further experiments are needed to determine what effect treatment earlier than on day 10 after turnout might have on the dose requirements and the acquisition of immunity.

Trials 1 and 3 showed that single-dose treatments with toltrazuril at $20 \mathrm{mg} / \mathrm{kg}$ on day 10 after turnout was very efficacious in preventing clinical symptoms due to the coccidial infection. Two doses of $10 \mathrm{mg} / \mathrm{kg}$, given either on days 10 and 11 , or on days 10 and 20 after turnout, were less effective in this respect, since diarrhoea occurred in some of the lambs given 
the latter treatments in Trial 1. Moreover, 2 treatments are more time-consuming than 1 , so that a single treatment will be preferred in the field. Trial 3 indicated that single doses of toltrazuril at $15 \mathrm{mg} / \mathrm{kg}$ on day 10 also were sufficient to protect the lambs from being severely affected by the initial coccidial infection on pasture.

In Trial 2 it was difficult to decide to what extent the concurrent $\mathrm{N}$. battus infection contributed to the clinical symptoms occurring in different groups. The magnitude of the $\mathrm{N}$. battus faecal egg counts on days 21 and 28 , and the occurrence of high pasture larval counts of Nematodirus at the time of turnout (determined as part of another investigation) strongly suggested that the lambs had acquired a severe infection with $\mathrm{N}$. battus. Clinical symptoms due to a $\mathrm{N}$. battus infection normally occur towards the end of the prepatent period of the parasite, i.e. when the faecal egg counts are still negative or low. Thus, in Trial 2, the acute phase of the $\mathrm{N}$. battus infection obviously coincidied with the peroid when the lambs actually showed diarrhoea, but also with the period when coccidiosis usually occurs. However, it seems justified to attribute the clinical symptoms (abnormal faeces) of the toltrazuril-treated lambs in large part to the concurrent infection with $\mathrm{N}$. battus. The clinical symptoms of the untreated lambs were probably caused jointly by the coccidia and $\mathrm{N}$. battus. This conclusion is supported by the findings in Trials 1 and 3 , which showed that a single dose of $20 \mathrm{mg} / \mathrm{kg}$ on day 10 was very effective in preventing diarrhoea. The coccidia may, however, have contributed to the softening of the faeces of the lambs of group 2, since several lambs in the corresponding group in Trial 3 had pastelike faeces. The low faecal oocyst counts of both toltrazuril-treated groups on day 17 also indicate that the coccidia did not cause the clinical symptoms seen in these groups. Moreover, the treatment with toltrazuril was clearly beneficial to the lambs in groups 2 and 3 , as they had better weight gains and significantly lower faecal consistency scores than the controls when all sampling days were considered collectively.

The effect of treatment with toltrazuril on weight gain was variable. In Trial 1 there were no significant differences between the. groups, whereas in Trials 2 and 3 , the treated lambs had significantly better weight gains than the controls during parts of the trials. However, in trials based on naturally acquired 
coccidial infections, there will be considerable variations among the lambs with respect to the magnitude, the composition, and the time of ingestion of the infective doses. Hence, the severity and the time of onset of clinical signs will vary, especially within the untreated groups. This will reduce the chances of obtaining significant differences in weight gain between (small) groups, even though the numerical differences are considerable. Not infrequently, lambs on pasture become so severely infected with coccidia that they either die or recover very slowly, showing a poor growth for a prolonged period. Thus, the use of an anticoccidial drug that is capable of preventing the occurrence of severe coccidiosis with associated deaths or chronically stunted lambs, may be economic, even though the treated lambs on average show a moderate reduction in weight gain during the acute phase of the infection.

This study showed that single-dose treatments of lambs with toltrazuril at 15 or $20 \mathrm{mg} / \mathrm{kg}$ on day 10 after turnout were capable of controlling the severity of, or preventing, coccidiosis due to the initial coccidial infection on pasture. Hence, the use of toltrazuril seems to be an effective and simple method for the prevention of severe outbreaks of coccidiosis in young lambs on pasture. Moreover, medication of naturally infected lambs with toltrazuril on day 10 after turnout will markedly reduce the excretion of oocysts for a prolonged period, and thus lessen the contamination of the pastures with coccidial oocysts.

\section{ACKNOWLEDGEMENTS}

The authors thank Dr. A. Haberkorn, Bayer AG, Wuppertal, for helpful suggestions during the planning of the trials and for providing us with toltrazuril (Bay Vi 9142). Sincere thanks are due to J. J. Nedkvitne, Agricultural University of Norway, Ås, for his co-operation in Trial 3. Further, we would like to thank B. A. Øien and S. L. Rolstad for technical assistance.

\section{REFERENGES}

Haberkorn, A. \& H. P. Schulz: Experimental chemotherapy of mammalian coccidiosis with Bay g 7183. Zbl. Bakt. Hyg., I. Abt. Orig. A 1981, 250, 260—267.

Haberkorn, A. \& J. Stoltefuss: Investigations of a new anticoccidial drug (BAY Vi 9142). Zbl. Bakt. Hyg., I. Abt. Orig. A 1984, 258, 426.

Helle, $O .:$ Coccidiose hos sau. (Coccidiosis in sheep). Medlemsbl. norske Vet.-Foren. 1964, 16, 117-127. 
Helle, O.: Winter resistant oocysts in the pasture as a source of coccidial infection in lambs. Acta vet. scand. 1970, 11, 545-564.

Helle, O.: Gastrointestinal parasites in sheep on lowland pastures in eastern Norway. Acta vet. scand. 1971, Suppl. 34, $118 \mathrm{pp}$.

Helle, O.: Behandling av lam mot coccidiose. (Anticoccidial treatment of lambs). Norsk Vet.-tidsskr. 1981, 93, 351-352.

Helle, O. \& M. Hilali: Differentiation of Eimeria species infecting sheep during the grazing season on permanent and new pastures under Norwegian conditions. Acta vet. scand. 1973, 14, $57-68$.

Mehlhorn, H., G. Ortmann-Falkenstein \& A. Haberkorn: The effects of sym. Triazinones on developmental stages of Eimeria tenella, E. maxima and E. acervulina: $A$ light and electron microscopical study. Z. Parasitenkd. 1984, 70, 173-182.

Rose, M. E.: Host immune responses. In: Long, P. L. (ed): The Biology of the Coccidia. University Park Press, Baltimore 1982, pp. $329-371$.

\section{SAMANDRAG}

Førebygging av koksidiose hos naturleg infiserte lam på beite med toltrazuril.

Ulike dosar av toltrazuril (Bay Vi 9142) vart gitt profylaktisk til lam som hadde vorte naturleg infiserte med koksidiar like etter utslepp på beite. Effekten av middelet vart vurdert ved å samanlikna feceskonsistens, oocystetal og tilvekst hos handsama og uhandsama lam. Ein einskild dose på $20 \mathrm{mg} / \mathrm{kg}$ av toltrazuril gitt på dag 10 etter beiteslepp hindra nesten fullstendig utbrot av koksidiose i 2 fors $\phi \mathbf{k}$. I eit tredje fors $\varnothing \mathbf{k}$ var lamma samstundes infiserte med Nematodirus battus, slik at den kliniske effekten av toltrazuril delvis vart maskert. Lam som fekk ein einskild dose på $15 \mathrm{mg} / \mathrm{kg}$ på dag 10 etter beiteslepp, synte berre milde symptom på koksidiose. To dosar på $10 \mathrm{mg} /$ kg, gjevne anten på dag 10 og 11, eller på dag 10 og 20 etter beiteslepp, var ikkje så effektive til å førebyggja diaré som ein einskild dose på $20 \mathrm{mg} / \mathrm{kg}$ på dag 10 . Alle dei nemnde dosane av toltrazuril førte til ein drastisk reduksjon i produksjonen av oocyster, med størst reduksjon for dosen på $20 \mathrm{mg} / \mathrm{kg}$. Lam handsama med toltrazuril på dag 10 etter beiteslepp var delvis immune mot den naturlege reinfeksjonen med koksidiar like etter handsaminga, og hadde, som dei uhandsama lamma, ein sterk nok immunitet til å motstå den kontinuerlege reinfeksjonen med koksidiar seinare $\mathrm{i}$ beiteperioden.

(Received December 30, 1985).

Reprints may be requested from: B. Gjerde, the Department of Internal Medicine I, Division of Parasitology, Norwegian College of Veterinary Medicine, P. O. Box 8146 Dep., N-0033 Oslo 1, Norway. 